\title{
Realistic Exploration of Watercolor Paintings
}

\author{
Ping Li
}

The experimental art department, Xi'an Academy of Fine Arts, 710065

\section{Keywords: Ontology; Realism; Expressionism; Contingency}

\begin{abstract}
The painting has undergone a long-term development process. The status quo of art in every age fully demonstrates that "truth seeking" has almost become the artist's pursuit of instinct, and there are many artists in the history of art who work tirelessly for "truth-seeking". They are the truth seeker of themself and also the seeker of truth under the appearance of this world. This article is divided into three chapters. In the first chapter, it mainly describes various artistic affinities in art history with the argument of "function theory" of art, which is similar to aesthetic and ugly appreciation, emotion and logic, naturalism and abstractionism, form and content. These disputes are like the general tributary of a huge river, rich but not divorced from the pursuit of truth and essence from different aspects. In the second chapter, it further discusses the "truth seeking" from the choice of theme and painting style by taking the watercolor works of Andrew Wyeth and Marlene Dumas as examples respectively. The third chapter summarizes the above two chapters. No matter from which point of view, "truth seeking" is not only a sincere attitude of creation or a true reflection of objective things, it is honesty to painters, viewers and paintings.
\end{abstract}

\section{"Theory of Function" of Art}

The artist's creative activity, as a kind of mental activity, is the process of receiving and reacting to the signals given by objective things. It is also for this reason that artists often act as stewards of the objective or subjective opinion of the human world and social formations. The intrinsic value of an artist's art works is generated when it comes to acting on things around it because of its intrinsic, individual, independent emotions.

There are different opinions on the "theory of function" of art. There have been many controversies on history such as aesthetics and ugliness, emotion and logic, naturalism and abstractionism, form and content. Studying the course of their controversy, it is actually a very permanent change in art itself.

The emergence and development of aesthetic awareness can not be separated from human social practice. Art was once the highest form of human aesthetic activity in this evolutionary process. However, at the end of the nineteenth century, the recognition and expression of the so-called "ugly" represented by artists such as Baudelaire broke the aesthetic, elegant and moral sensory perceptions built by mankind in the past several thousand years. Until now, the topic of aesthetics and ugly appearance seems to have long been out of controversy. Romanticism and Baroque exert the most emotional influence on the main body of art. Women painted by Rubens always highlight the tension and emotional language in the most powerful trend. And thousands of years later, the body of a woman turns into a cold blue in the action painting of Klein, with the hidden logic behind her. Caravaggio's portrayal of naturalism seemed incredibly among the painters who main painted literature, religion and history at the time. But this kind of naturalism seems to have become a poor portrayal of nature in the 20th century. The most common and constantly circulating topic of discussion is probably about the importance of "form or content" in art. Before the emergence of the Impressionist, art relied more on such thematic extensions as literature, history or religion. The Impressionism made light and color a protagonist of paintings, completely breaking the "story." Then, Cubism made each line, color, the structure of painting and others, that is, form the dominant figure in painting. However, just as "formality" prevailed in the early twentieth century, the demand that "art should reflect social reality" be reintroduced. In the hundred years that followed, neither of them stopped changing positions in an art-focused sense. Whenever art exists for "art" itself, some people stand up and actively call for "the social responsibility of art." When the social responsibility 
of the art is brought into full play, some people stand up to come forward with the idea that "art should not be reduced to a social tool but should be more purely".

All the above controversies and arguments have occupied an important position in the history of art. But in the final analysis, all this is like a number of tributaries of a huge river, which is rich but not divorced from it.

The so-called "beauty" and "ugliness" may be roughly understood as "the art of the sun god" and "the art of Bacchus" discussed by Nietzsche in "The Birth of a Tragedy". The former tells the people a truly orderly world. It is bright, moral, elegant and is the reality of vision. Meanwhile, is it not another intrinsic truth that the latter exposed nakedly the non-morality and non-orderliness hidden under the appearance and warned people to face suffering and darkness? By the same token, in the case of painting, if emotion is a certain truth of the artist at subjective emotion level, then logic exists as the reality of another objective judgment. If naturalism is the visible, real expression of what the objective world presents to humans, then abstractionism is trying to discover the invisible reality that is hidden. If the form is the true language of painting and art, then the content is the real feeling of objective things.

No matter which tributary, art in the self-exploration of the road, always spares no effort to dig out the real and to explore the subtle existence that is not easy to find.

\section{Realistic Exploration in Painting}

The most basic meaning of "truth" can be interpreted that it is consistent with the objective things and contrary to "false" and "pseudo". As mentioned above, in a broad sense, the "truth" in art is not only equivalent to the "lifelike" and "sincere" literally understood. It is a broader range of multi-disciplinary accommodation. Through creative work, artists refine, process and express natural and human societies. It is nothing more than a more essential truth, that is, the true appearance and laws of everything. For example, the philosophical and lyricistic features shown in Chinese literati paintings distinguish them from artisan paintings and courtyard paintings. As we all know, because the literati's pursuit of the literati thought outside the painting makes the images expressed by him not only the pure natural scenery but also the incarnation of a gentleman. The literati can use this to express various emotions in his heart and switch between Confucianism and Taoism with its own personal role, which is the exploration of the relationship between mankind and society, man and nature behind the scenes. From the painter's own sentiments or painters, everything comes from the pursuit of a deeper and more realistic world.

There are many artists in the history of art who make unremitting efforts for "truth-seeking". Taking watercolor as an example, as a kind of western painting, it is more realistic in a certain degree. The western traditional watercolors emphasize light, brightness, volume, etc. The same as oil painting performance, but at the same time is different from the oil and has hearty, water intertwined, realistic with the characteristics of freehand writing, which allows the expression of content and artistic expression are more "truth-seeking." After thousands of years of development, artists have contributed to it. In the following, we will take the individual artists' watercolor works as an example to discuss "truth seeking" in watercolor from the perspectives of "theme" and "painting style" respectively.

\section{Realistic Exploration of Theme}

Wyeth Andrew. Painting is essentially the expression of human cognition of the world. Artists must explore and develop in their own minds in order to establish "truth" in their works and to use them as a spiritual carrier.

As one of the greatest painters in the 20th century in the United States, Wyeth Andrew (1917 2009) has the characteristic of restlessness and tranquility distinguished from that of modern times in the subject of painting. His realism theme was recognized and made a breakthrough in the middle-class mainstream art trends and concepts in the United States.

To Wyeth, he was familiar with the slightly sad Pennsylvania Valley and Maine coastline, barren 
wilderness and shabby wooden houses, bored little girls and quiet soft lights, vultures hovering in lonely skies and that desolate beach. In his writing, has emboldened the patriots who are full of melancholy to fight against their destiny, as well as their complaints about suffering and loneliness, and the unease and sense of loneliness they have shown have become the proof of artists' pursuit of strong individual freedom spirit.

Most of Wyeth's works are dry-ink watercolor paintings. Unlike traditional flow-through watercolors, dry-stroke watercolors can create richer and more specific details. Because of the less water in the pen, the pigments overlap one another Painting. With the increase of watercolor thickness and level, paintings present a delicate and exquisite visual effects. Wyeth put his own visual experience into the strong local realism and realistic works, with precise and lifelike modeling ability to realize the blending of man and nature. The simple theme shows the tough and persistent Puritan inner world of painters. He used to draw many windows of watercolor material, some of these windows for indoor perspective, some for outdoor perspective. Shabby windows and corners are always consciously or unconsciously placed a few pieces of fruit or an old fish pole, which are too plain to seem to have no characteristics at all. However, even the most common items in life are still filled with a slight sentiment in Wyeth paintings. All the paintings pour their own appeals in different corners, such as an old cowboy clothing, every piece of wasteland, every late return of farmers and every quiet girl painted by Wyeth.

Wyeth's work also has a far-reaching impact on the art of scuffle art in China in the 1970s and 1980s (represented by He Duoling and Ai Xuan). His wretched and confused life revealed in his grim realistic painting echoed the hearts of Chinese artists who had just escaped the imprisonment of the "Cultural Revolution." In addition, Wyeth is also admirable for his persistence.

Wyeth deeply penetrates the surface of nature, and succeeds in merging the objective reality and the subjective feelings in the works to form the thoughtful works with deep connotation. His observation of nature and life all showed his subtle observation and keen sensibility, and his choice of creative themes was even more in line with his own heart and unremitting choice. In the mainstream of the complex forms of modernism he chose resolutely toward a seemingly too traditional direction and made his own unique achievements. His theme deep into his own heart, life and the world he concerned about, which is closely related to the most real face to himself and it is also the most authentic expression to others.

\section{Realistic Exploration of Painting Style}

Marlene Dumas. Painting is essentially related to man, thought and the world in which we live. As a two-dimensional visual expression, the painting is making ever more sincere requests for every brush stroke and every color.

Marlene Dumas, born in the mid-20th century, is often referred to as a "spiritual expressionist". Her fluent and pungent colors are often those who are weak, vulnerable and easily vulnerable people, but she never shows her audience any consolation. However, she provokes some disturbing fear to viewers with intense color contrast and approaching composition. To some extent, her paintings have no the function of being used as an image-sharing and narrative. Her paintings are usually thin and without any exquisite decoration, with thick lines and direct and simple brush style, which gives a strong visual impact and inner touch.

Dumas's watercolor creation is very unique and full of chance. She splashes the color on the paper, then draws the outline with the flow of water color, and then draws the facial features with charcoal, which is similar to "Ink and wash landscapes" of Wang Wei who is a poet and painter in the Tang Dynasty. In fact, in such a process, the materials occupy the leading position, which is just to retrieve the dignity of the painting itself. In a series of watercolor works entitled "Wilt" (Figure 1), created in 1994, Dumas brought the uncontrolled and accidental freedom of water and color to the limits of extreme. The technique of flowing and fading makes the picture look both special and plentiful. These images of people injured by love are different and very unease under fear and sadness. At the same time, she expands each portrait to a macro viewing mode and juxtaposes them, increasing the sentiment and suffering by this method. 
Another familiar painting, Painter (Figure 2), was created by Dumas on the source of her daughter's childhood photographs. The little girl in the picture - or the child who is hard to read naked body facing the viewer, with blue right hand and red left hand weakly hanging on both sides of the body. Her eyes have solemn and serious which is inconsistent with her age, without a little naive and beauty. That unspeakable emotions was reflected mysterious and claustrophobic in the cold gray simple background.

As the most famous contemporary feminist artist, Dumas presented her view of the real world to her audience from a unique perspective. She did not simply portray life, but led us to explore an extremely subtle real world with her keen perception, where weakness and suffering is real, and every embellishment and indictment of life is real.

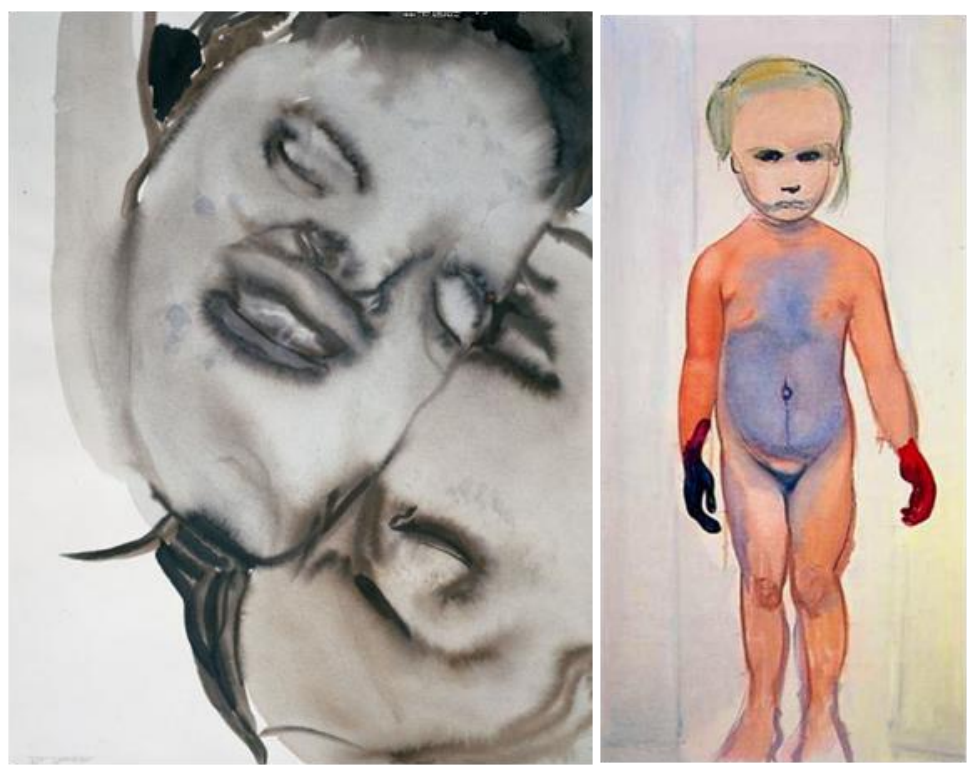

Figure 1. Wilt

Figure 2. Painter

\section{Conclusion}

Whether from the choice of the theme or from the creative point of view, "truth-seeking" all means for their own honesty, the viewer's honesty and the honesty of painting. Those works that have a place in the history of art tend to dare to break the stereotype and come into our hearts in a modest way and in a true and sincere state and become the new "leader." Paul Sandby, the first watercolor painter in the history of British painting, his creative research and bold experiments, as well as closer to inner self and more content-rich content, made it very important for later watercolorists.

Contemporary art is constantly expanding its own production under the impact of diverse forms and various materials and concepts. Painting is facing an unprecedented test. However, what is certain is that "truth seeking" is almost the basic instinct of art for any artist or art work. Therefore, how to explore the more subtle real world hidden under the surface of life and truly face themselves and paintings has become the direction that artists are trying their best to pursue.

\section{Reference}

[1] "The Birth of a Tragedy" [Germany] Friedrich Nietzsche and G. P. Zhou. Nanjing. Yilin Press. 2014.

[2] "History of Western Art" X. L. Ma. Shijiazhuang. Hebei Fine Arts Press. 2009.

[3] "Realistic Painting in 20th Century" [English] Prenvalle Edit and Y. Ying Translate. Shanghai People's Fine Arts Publishing House. 2015.

[4] "Spirit in Art" [Russia] Kandinsky and Z. W. Li and others. Beijing. Renmin University of China Press, 2003. 
[5] "A Comment on the Emotional World of Neo Expressionist Painting" Y. J. Zheng. Popular Literature and Art, 2010 (4).

[6] "Manifesto Declaration" J. C. Feng. Culture and Arts Press. 2007.

[7] "The Art World of Andrew Wise" Z. G. Shao. Popular Literature and Art. 2014 (6).

[8] "Marlene Dumas's Works" X. Jing. Popular Literature and Art. 2014 (9).

[9] "Art and Vision Consciousness" [US] Rudolph Arnheim and S. Y. Teng. Chengdu, Sichuan People's Press, 2006.

[10]"Art History of 20th Century" [Germany] Uwe Schneider and J. H. Shao and others. Beijing. China Federation of Literature Press. 2014. 